\title{
Effect of retorting and oven cooking on the nutritional properties of beef frankfurters blended with palm oils
}

W. I. WAN ROSLI1, A. S. BABJI2, A. AMINAH2, S. P. FOO3 \& O. ABD MALIK4

1School of Health Sciences, Universiti Sains Malaysia, Kelantan, Malaysia, 2School of Chemical

Sciences and Food Technology, Universiti Kebangsaan Malaysia, Bangi, Selangor, Malaysia,

3Carotino Sdn. Bhd., Jalan Besi Satu, Johor, Malaysia, and 4Food Technology Centre, MARDI,

Kuala Lumpur, Malaysia

\begin{abstract}
The effect of retorting and oven cooking on the nutritional properties of beef frankfurters blended with palm oil (PO), red PO35 and red PO48 were compared against the control beef fat treatment. Red PO oven-cooked beef frankfurters resulted in a significant loss of vitamin E from 538.5 to $287.5 \mathrm{mg}$ after 6 months. Oven cooked sausages stored at -18 _C and retorted sausages stored for the 6 months of shelf studies resulted in more than $90 \%$ loss of a-carotene and b-carotene in red PO beef frankfurters.

Cholesterol was reduced at the range of $29.0-32.2 \mathrm{mg} / 100 \mathrm{~g}$ when beef fat was substituted with palmbased oils, in beef frankfurters. Differences of heat treatments did not significantly change THE cholesterol content, within all treatments. This study showed the potential of utilizing red palm oils as animal fat analogues in improving vitamin $\mathrm{E}$, reducing cholesterol but not carotenes in beef frankfurters.
\end{abstract}

Keywords: Tocopherol, tocotrienol, carotene, cholesterol, oven-cooked, retort, beef frankfurter, red palm oil, palm oil

Introduction

Animal fats are added to meat products for reasons of cost-saving, texture and flavour.

With the increase in the production of processed meats, animal fats and skin have become essential items in the formulation of meat products such as nuggets, burgers, balls, hot dogs and bologna (Babji et al. 1998). As more evidence concerning the benefits and risks associated with dietary nutrients are emerging in both the scientific field and the mass media, today's consumers are more informed on the link between health and diet. Levels of saturated fat and cholesterol have been a major problem, resulting in meat products becoming the subject of scrutiny by nutritional, medical, and consumer groups (Colmenero 1996; Chizzolini et al. 1999; Resurreccion 2004; Ollberding 2008). Palm oils and red palm oils (RPOs) are cholesterol-free and naturally contain tocopherol, tocotrienols and carotenoids. These functional properties of palm fat raw materials, when used in the making of processed meats, may result in better 
quality products in the market THAT are safer and nutritious. The most common synthetic antioxidants used in the food industry are butylated hydroxytoluene, butylated hydroxyanisole (BHA) and tert-butylhydroquinone. However, these synthetic antioxidants are banned in several countries due to their carcinogenic risk (Wanasundara and Shahidi 1998; Tang et al. 2001). For these reasons, natural antioxidants are very important for human health. Therefore, the interest in natural antioxidants, especially of plant origin, has greatly increased in recent years (Jayaprakasha and Rao 2000; Baydara et al. 2007). Natural antioxidants have become a part of the diet in human nutrition with the aim of decreasing the risk of disease such as coronary heart disease, cancer (Higdon and Frei 2003; Bozkurt 2006) and also diabetes (McCune and Johns 2002). Recently, natural grape seed, rosemary and oregano extracts are reported to have more antioxidant activity over the storage period than did the synthetic butylated hydroxyanisole and butylated hydroxytoluene (Sasse et al. 2009).

In PO and RPO, vitamin E occurs as a mixture of tocopherols ( $30 \%)$ and tocotrienols ( $70 \%)$. Crude PO consists of $22 \%$ a-tocopherol, $20 \%$ a-tocotrienol, $46 \%$ g-tocotrienol and $12 \%$ d-tocotrienol (Hashimoto et al. 1980). Crude PO and RPO contain between 500 and 700 ppm carotenoids (Ooi et al. 1996). The major components are a-carotene (35-37\%) and b-carotene (47-56\%). These carotenoids have provitamin A activity. Carotenoids are often thermally degraded and removed during the deodorization stage of the refining process. In crude palm oil (CPO), these carotenoids appear to offer some protection against oxidation by themselves, being oxidized first prior to the oxidative attack on the triglycerides (Choo et al. 1993).

Vitamin E compounds (tocopherols and tocotrienols) are well recognized for their effective inhibition of lipid oxidation in foods and biological systems (Van Acker et al. 1993). Since vitamin $E$ is only synthesized by plants, it is a very important dietary nutrient for humans and animals (Hess 1993). Many researchers reported that the antioxidant activity of tocopherols and tocotrienols is mainly due to their ability to donate their phenolic hydrogens to lipid free radicals (Burton and Ingold 1989; KamalEldin and Appelqvist 1996). The relative antioxidant activity of tocopherols in vivo is reported in the order $a>b>d>g$ (Kamal-Eldin and Appelqvist 1996).

Carotenoids have been cited as responsible for the reduction of the risk of developing degenerative diseases such as cancer, cardiovascular disease and macular degeneration (Marcela et al. 2004). Carotenoids have also been shown in a number of studies to be able to act as a radical scavenging antioxidant. The carotenoid pigments can be decolorized by bleaching alone or with high-temperature treatment (110-149 F). Conventional deodorization is done at 182-218 C (Onyewu et al. 1996). The carotenoid can also be degraded at deodorization temperatures of $260 \mathrm{C}$ and $219 \mathrm{C}$. Chiu and coworkers suggested that the separation by membranes is effective in the recovery of carotenoids from RPO, presenting a high potential regarding the use for industrial application in the near future (Chiu et al. 2009). Another study on the modification method to minimize losses of carotenoids and tocopherols during high-performance liquid chromatography (HPLC) analysis of RPO was performed by Lietz and Henry (1997). They suggested that mild hydrolysis with the use of Candida cylindracea lipase enables quantitative analysis of carotenoids and tocopherols in RPO without isomerization or destruction of either carotenoids or tocopherols (Lietz and Henry 1997).

CPO contains about 800 ppm vitamin $\mathrm{E}$, and about $70 \%$ of it remains in refined, bleached and deodorized (RBD) form. Most of the palm oil products sold in the market are in the RBD form. Refining is necessary to remove impurities and contaminants that 
affect the quality of the end products (Ooi et al. 1996). RBD palm oil contains about 300-500 ppm tocopherols and tocotrienol and no carotene (MPOB 1981). In view of the important of carotenes, and in order to sustain the carotenes in palm oil, a molecular distillation process has been developed. The technology involves pretreatment using phosphoric acid, followed by bleaching earth. The deodorization and deacidification is then carried out using molecular distillation unit under low temperature and pressure (Choo et al. 1993). CPO that had undergone this patented process yielded deacidified and deodorized RPO with various concentrations of carotene content. RPO35 and RPO48 contain approximately 350 and 80 ppm carotenes (Choo et al. 1993).

In recent years, there are few studies reporting on the effects of cooking/processing on the carotenoid composition in vegetables (Padmavathi et al. 1992; Gayatahri et al. 2004; Marcela et al. 2004) but lacking in processed meat products. Researchers believe that palm fats make sausages and other meat products better and healthy (Babji et al. 2001; Wan Sulaiman et al. 2001). Improved nutritional properties including vitamin E content of chicken frankfurter where chicken oil was substituted with RPO was reported by (Wan Sulaiman et al. 2001). Optimizing palm oil and palm stearin utilization for sensory and textural properties of chicken frankfurters was studied by Tan et al. (2004). They reported that texture profiles of the chicken frankfurters containing PO (slip melting point [SMP] 54.9) and chicken fat were quite similar, but increments of palm stearin (SMP 34.7) raised hardness, chewiness, and shear hardness of the frankfurters. The higher the SMP of palm oil, the lower the acceptance of frankfurters in most of the sensory attributes tested. Our previous study on utilizing palm oil in beef patty and chicken frankfurter suggests that vitamin $E$ is highly stable to sterilization compared with oven cooking (Wan Rosli et al. 2006).

Since RPO contains high concentrations of vitamin E, pro-vitamin A and no cholesterol, its stability during oven cooking and retort treatment of palm-oil-based beef frankfurter has never been studied. Hence, the present research focused on the nutritional value (vitamin E, carotenes) and cholesterol content of beef frankfurters blended with PO and red PO (RPF35 and RPF48, respectively) during cooking and storage. The decrease in concentration of vitamin $\mathrm{E}$ homologues and carotenes during cooking and storage were also monitored.

\section{Materials and methods}

\section{Sample preparation}

Four beef frankfurter formulations were compared. Each formulation contained 15\% fat from beef (control), palm oil (SMP 41-44 C, iodine value (IV) 45-50), RPO35 (SMP 33-37 C, IV 48-53) or RPO48 (SMP 46-50 C, and IV 42-46). Palm oil was supplied by Cargill Fats and Oils Specialty Company (Cargill Fats and Oils Specialty, Port Klang, Malaysia) and the RPO (yellow in colour) was supplied by the Carotino Company (Carotino Pte. Ltd, Johor, Malaysia). The palm oil and RPO (RPO35 and RPO48) is called raw fat before being incorporated in the sausage formulation. Frozen New Zealand beef and beef fat (raw fat) were purchased from Lucky Frozen Pte. Ltd. Dry ingredients (Table I) such as potato starch, isolated soy protein, salt, sodium tripolyphosphate, sodium erithrobate, nitrate, spices and seasoning were purchased from Mackessen Pte. Ltd (Selangor, Malaysia). 
Table I. Beef frankfurter formulations.

\begin{tabular}{lc}
\hline Ingredient & Percentage \\
\hline Beef & 52.00 \\
Fat (beef fat, palm oil, RPO35 and RPO48) & 15.00 \\
Water & 24.91 \\
Potato starch & 2.50 \\
Isolated soy protein & 3.00 \\
Salt & 1.10 \\
Sodium tripolyphosphate & 0.30 \\
Spices and seasoning & 1.14 \\
Sodium erithrobate & 0.03 \\
Nitrate & 0.02 \\
Total & 100.00 \\
\hline
\end{tabular}

\section{Method of production ofbeefsausages}

The finished beef batters were manually stuffed into $26 \mathrm{~mm}$ Viscofan cellulose casings using a stuffer (FDIC, Hamburg, Germany). Two types of cooking methods on the same four beef frankfurter formulations were evaluated. The oven-cooked sausages were cooked in an oven, with a staggered time and internal sausage temperature increments, starting with $55 \mathrm{C}$ for $20 \mathrm{~min}, 65 \mathrm{C}$ for the next $20 \mathrm{~min}, 75 \mathrm{C}$ for $20 \mathrm{~min}$ and $80 \mathrm{C}$ for $15 \mathrm{~min}$. A meat thermometer probe was attached to one of the sausage links to record the internal temperature changes of the sausages during cooking. After cooking, the frankfurters were cooled, weighed, peeled, and stored in the freezer at $18 \mathrm{C}$. Another half of the stuffed batters were manually placed into $17 \times 13 \mathrm{~cm}^{2}$ retort pouches and kept in the chiller at 2-5 C until ready for sterilization. The beef frankfurters in the pouches were then sealed, sterilized and retorted (Retort clutch Model H60, type C50; Tokyo, Japan) at $121 \mathrm{C}$ until an F-naught (FO) of 3.2 was reached. After retorting, the frankfurters were cooled and stored at room temperature. The processing of beef frankfurters was replicated twice.

Fat raw materials and fat extraction

The fat raw materials used in the sausage-making process consisted of beef fat, palm oil, RPO35 and RPO48. The same four types of fats were extracted (Kinsella et al. 1977) from the oven-cooked and retorted sausages at 0 and 6 months of storage. The extracted fats were stored at $-18 \mathrm{C}$ for further analysis and comparisons were made on vitamin $E$ and carotene content between the extracted fats and the raw fat materials. Raw fat materials were directly used for vitamin $E$ and carotene analyses.

Vitamin $\mathrm{E}$ analysis

Vitamin E was analysed using HPLC (model number LC240; Perkin Elmer, Massachusetts, USA) according to the method of AOCS (1992). Samples were injected $(20 \mathrm{ml})$ as peak responses of tocopherols and tocotrienols measured using a fluorescence detector with excitation and emission wavelength set at $290 \mathrm{~nm}$ and $330 \mathrm{~nm}$, respectively. The analyses used a stainless steel Lichrosorb (250 mm $4 \mathrm{~mm})$ column, and the solvent system was hexane:isopropyl alcohol $(99: 1, \mathrm{v} / \mathrm{v})$ at a flow rate 
of $1.0 \mathrm{ml} / \mathrm{min}$. Vitamin E content of frankfurter sample was determined in triplicate. The analyses were replicated twice.

\section{Carotene analysis}

Carotenes were determined using HPLC developed by Hart and Scott (1995) with some modifications. Before extraction of carotenes, the lipid extracts were saponified for 16 hours prior to extraction (Hart and Scott 1995).

\section{Calculation of percentage reduction biftamin $\mathrm{E}$ and carotenes during storage}

The percentage reduction of vitamin $\mathrm{E}$ and carotenes values during storage were calculated based on the values of extracted fats from sausages at 0 or 6 months, subtracted with values from initial raw fat materials, divided by the initial values of fats detected from raw fat materials. The raw fat materials (beef fat, palm oil, RPO35 and $\mathrm{RPO} 48$ ) are taken from the same batch of four types of fats used in the sausage-making.

\section{Saponification and extraction}

Duplicated $5 \mathrm{~g}$ lipid extracts were placed in 500-ml saponification flasks (covered with aluminium foil) together with $70 \mathrm{ml} 1 \%(\mathrm{w} / \mathrm{v})$ ethanolic pyrogallol and $20 \mathrm{ml} 50 \%(\mathrm{w} / \mathrm{v})$ $\mathrm{KOH}$. The flask was then purged with nitrogen gas for 30 min prior to agitation and shaken for $16 \mathrm{~h}$ at $20 \mathrm{C}$. All procedures were conducted in the dark. All glassware was also covered with aluminium foil.

\section{Preparation ofstandard a-carotene and b-carotene}

a-Carotene and b-carotene were dissolved in HPLC-grade hexane and made to volume with hexane to give a final solvent ratio of $1: 9 \mathrm{v} / \mathrm{v}$. All solvents contained $0.1 \%$ butylated hydroxytoluene. A mixed working standard solution was prepared, in the mobile phase, from individual stock solutions (Hart and Scott 1995). A calibration graph was prepared from the HPLC standard concentrations versus peak areas.

\section{Chromatography}

Carotene content was analysed using HPLC developed by Hart and Scott (1995). The HPLC system was an isocratic solvent delivery pump (Waters model 1515; Waters, Massachusetts, USA) coupled with an ultraviolet detector (Waters model 2487). The column system consisted of a $250 \mathrm{~mm} 4.6 \mathrm{~mm}, \quad 5 \mathrm{~mm}$ Bondapak octadecylsilane ODS ( $C_{18}$ ) analytical column (SGE) modified by the placement of metal frits. The mobile solvent system consisted of acetonitrile, methanol and dichloromethane $(75: 20: 5 \mathrm{v} / \mathrm{v} / \mathrm{v})$ containing $0.1 \%$ butylated hydroxytoluene. The prepared mobile phase was filtered through a $0.45 \mathrm{~mm}$ Whatman membrane filter and degassed using ultrasonic agitation. The flow rate was $2.5 \mathrm{ml} / \mathrm{min}$. Samples were injected via a micrometer syringe (model 705; Hamilton, Nevada, USA) loading injector fitted with a $20 \mathrm{ml}$ loop. Peak responses were measured at $450 \mathrm{~nm}$ using a Waters brand variable wavelength UV/Vis detector with an output to a chromatographic Breeze data handling system. 


\section{Cholesterotontent}

The cholesterol content was determined using a spectrophotometer (Bohac et al. 1988). The cholesterol was derived from the extracted fat from sausages, based on Kinsella et al. (1977), before spectrophotometry is determined. The cholesterol content is determined based on milligrams $\mathrm{g}$ of cholesterol, per $100 \mathrm{~g}$ fat, extracted from the beef sausages (wet samples).

\section{Statisticalanalyses}

Data obtained were tested for significance using analysis of variance and the Duncan multiple range test with SAS version 6.12 (SAS 1989). Significance was established at $P £ 0.05$ unless otherwise indicated.

Results and discussion

Vitamin E content in beeffrankfurter

a-Tocopherol in all retorted and oven-cooked beef frankfurters significantly decreased $(P<0.05)$ after 6 months of storage. All oven-cooked beef frankfurters blended with palm oil and RPO, except the control, significantly decreased $(P<0.05)$ in atocopherol concentration to a range of $54.5-72.5 \mathrm{mg} / \mathrm{g}$ (46-54\% loss) during frozen storage at $-18 \mathrm{C}$ after 6 months (Figure 1a and Table II). However, a-tocopherol was more stable in retorted beef frankfurters containing RPO3,5 which decreased from 113.5 to $64.5 \mathrm{mg} / \mathrm{g} \mathrm{(43 \% )}$ compared with palm oil retorted beef frankfurters that significantly decrease $(P<0.05)$ from 135.5 to $72.0(47 \%)$ after 6 months of storage (Figure 1a and Table II). A similar trend of reduction in a-tocotrienol concentration was also detected in both oven-cooked and retorted beef frankfurters. a-Tocotrienol in retorted beef frankfurters decreased by $66.5-85.0 \mathrm{mg} / \mathrm{g}(34-46 \%)$ with retorted beef substituted with RPO35 being the highest in a-tocotrienol concentration after 6 months of storage at room temperature (Figure $1 \mathrm{~b}$ and Table II). However, a-tocotrienol in all oven-cooked beef frankfurters significantly decreased $(P<0.05)$ by $53.0-68.5 \mathrm{mg} / \mathrm{g}$ (47-57\%), with oven-cooked beef frankfurters containing RPO48 being the lowest in a-tocotrienol concentration after 6 months of storage.

$\mathrm{g}$-Tocotrienol in all oven-cooked and retorted beef frankfurters recorded the highest concentrations and significantly decreased $(P<0.05)$ after 6 months of storage time (Figure 1c and Table II). However, the percentage loss in g-tocotrienol was lower than a-tocopherol and a-tocotrienol, being reduced by $29-38 \%$ or from 121.5 to $166.0 \mathrm{mg} / \mathrm{g}$ in retorted beef frankfurters and by $41-45 \%$ or from 116.5 to $130.0 \mathrm{mg} / \mathrm{g}$ in ovencooked beef frankfurters after 6 months of storage (Figure 1c and Table II). After

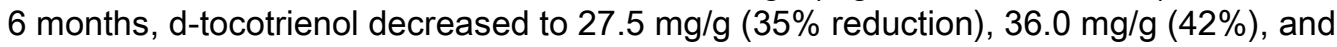
$32.5 \mathrm{mg} / \mathrm{g}(29 \%)$, respectively, for oven-cooked chicken frankfurter prepared with palm oil, RPO35 and RPO48 (Figure 1d and Table II). However, retorted beef frankfurter blended with palm oil recorded the lowest concentration in d-tocotrienol $(28.0 \mathrm{mg} / \mathrm{g})$ after 6 months, with retorted beef frankfurter blended with RPO35 being the highest concentration $(47.5 \mathrm{mg} / \mathrm{g})$.

All oven-cooked beef frankfurters substituted with palm oil, RPO35 and RPO48 decreased significantly $(P<0.05)$ from 501.0 to $285.5 \mathrm{mg} / \mathrm{g}(43 \%$ reduction), from 538.5 to $287.5 \mathrm{ng} / \mathrm{g}(47 \%)$ and from $482.5 \mathrm{mg} / \mathrm{g}$ to $261.0(46 \%)$ in item total vitamin E 


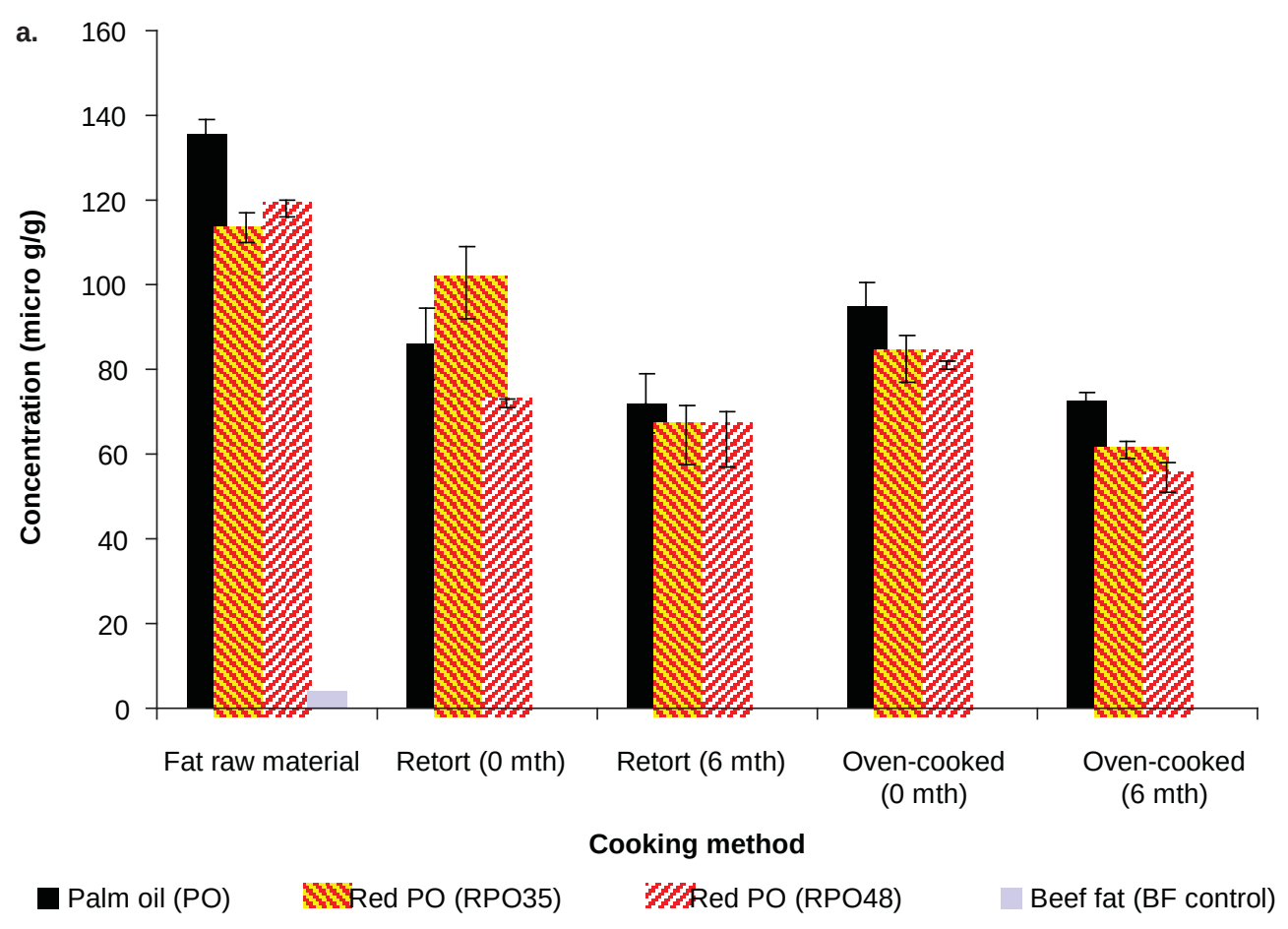

b.

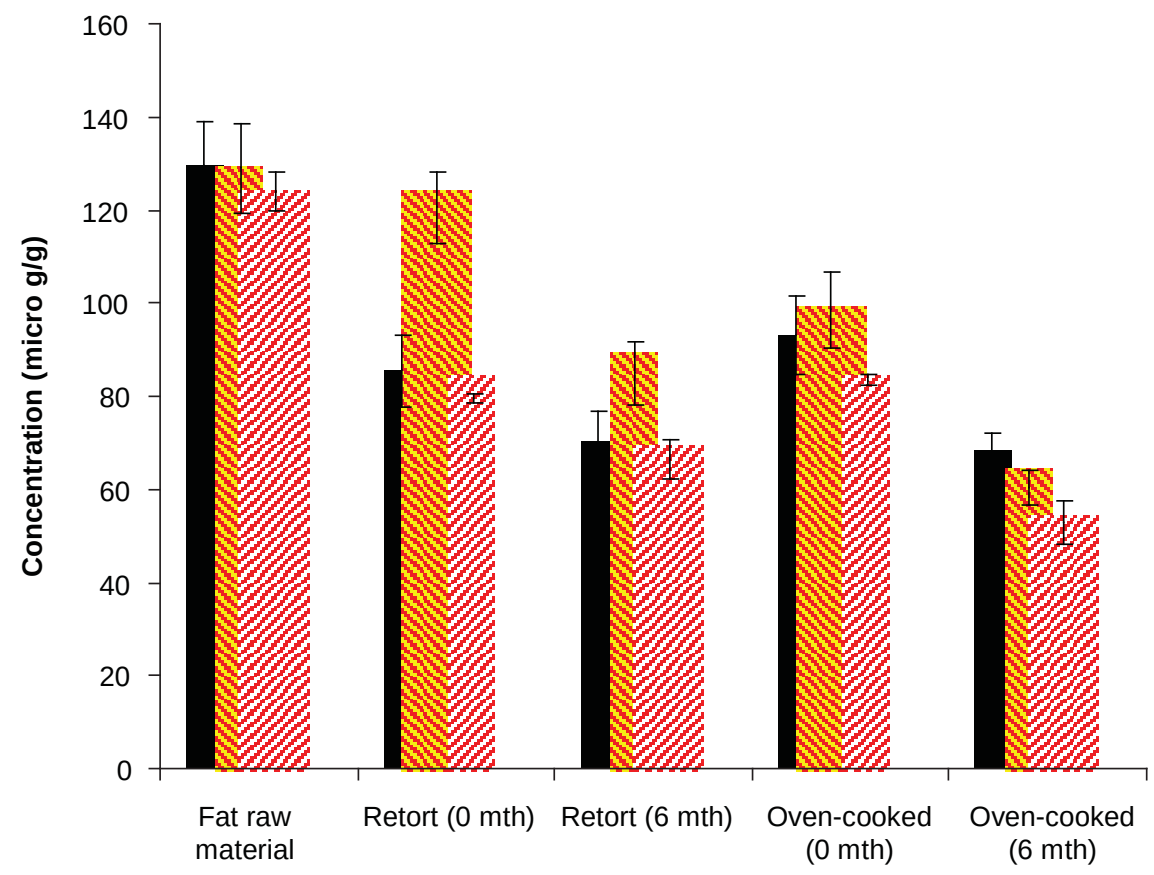

Palm oil (PO)

MNed PO (RPO35)

Cooking method

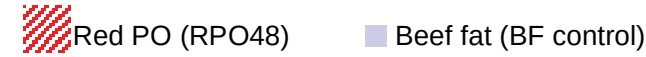

Figure 1. (Continued). 


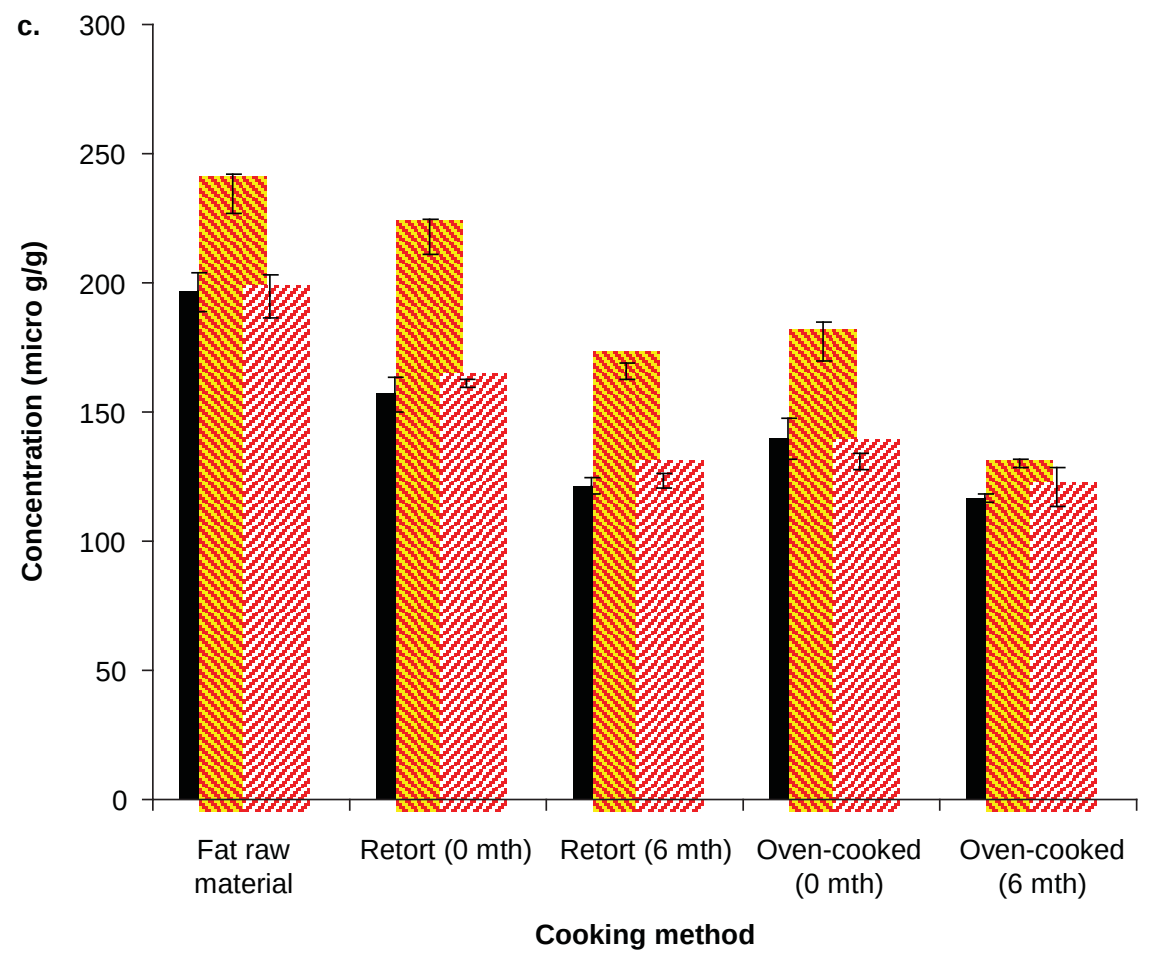

Palm oil (PO)

Red PO (RPO35)

U/Red PO (RPO48)

Beef fat (BF control)

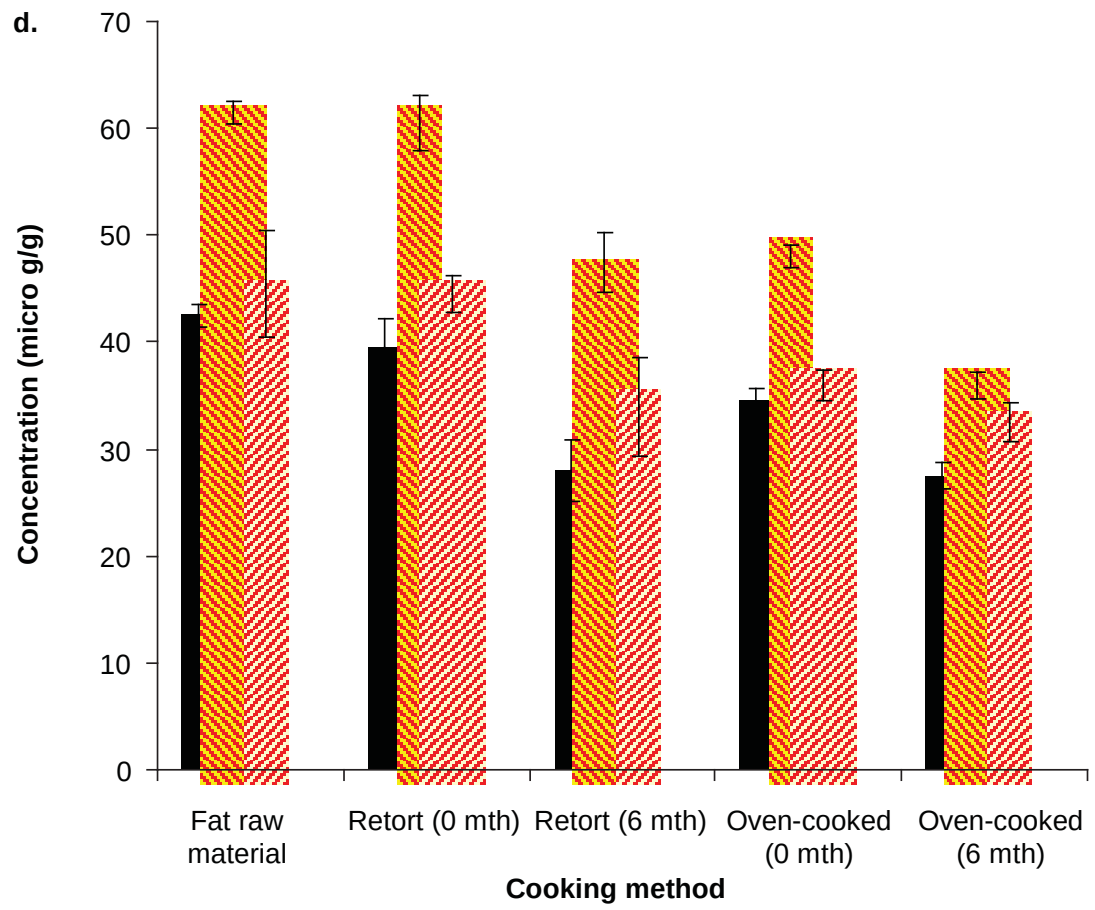

— Palm oil (PO) MNed PO (RPO35) WRed PO (RPO48) Beef fat (BF control)

Figure 1. (Continued). 


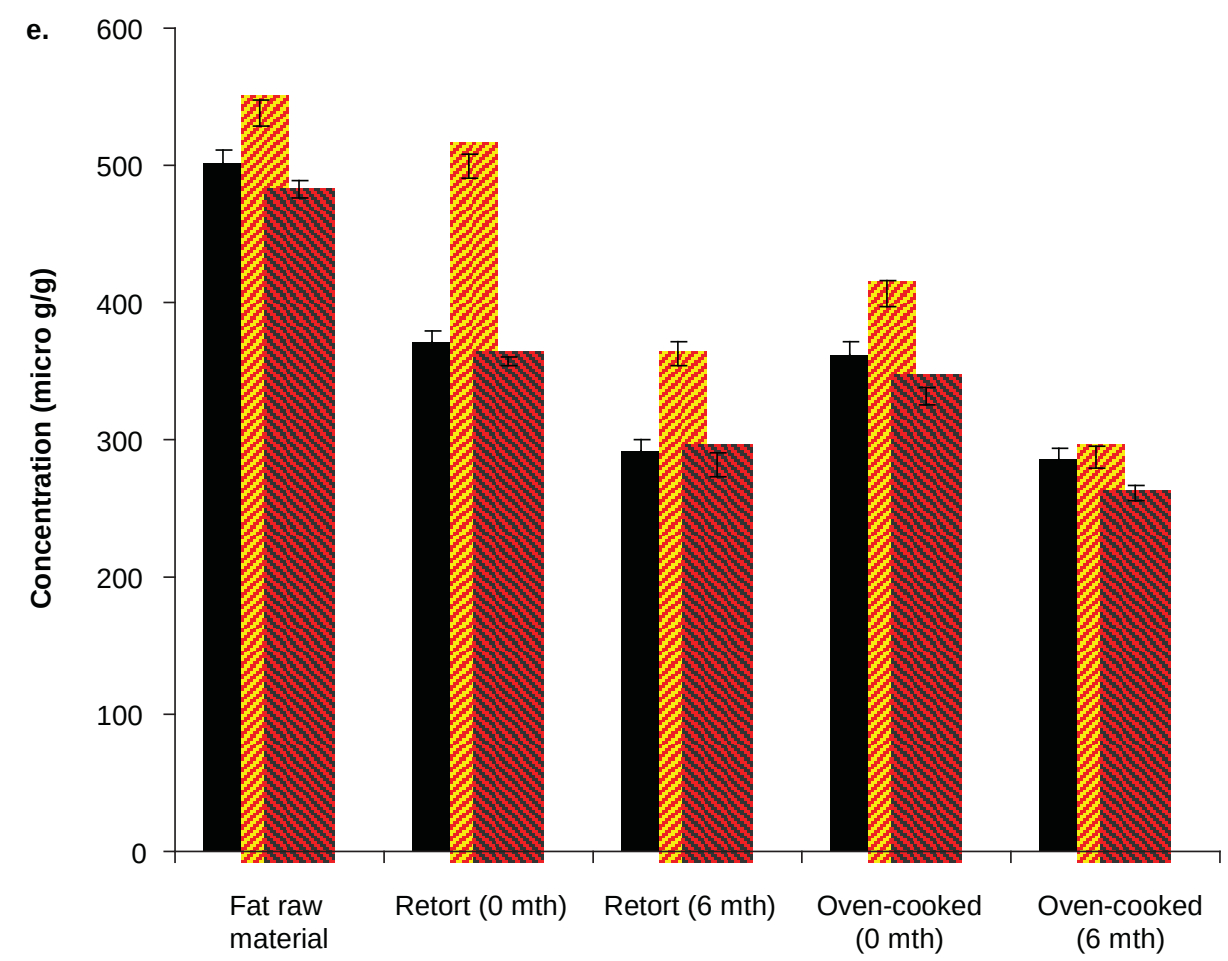

Cooking method

Palm oil (PO)

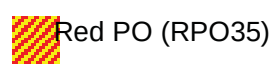

Ned PO (RPO48)

Beef fat (BF control)

Figure 1. Concentration of (a) a-tocopherol, (b) a-tocotrienol, (c) g -tocotrienol, (d) d-tocotrienol and (e) total vitamin $E$ for retorted beef frankfurter formulated with palm-based oils during storage for 6 months.

concentration, respectively, after 6 months of storage (Figure 1e and Table II). Total vitamin E concentration in retorted beef frankfurter blended with RPO35 was the highest, which accounted for $363.0 \mathrm{mg} / \mathrm{g}$ (33\% loss) after 6 months of storage (Figure 1e and Table II).

The initial amount of vitamin $\mathrm{E}$ detected in beef fat during this study was $4 \mathrm{mg} / \mathrm{g}$. However, this amount was completely destroyed after storage. The mean values of vitamin $E$ content in retorted and oven-cooked beef frankfurters stored at room temperature and $-18 \mathrm{C}$ significantly decreased $(P<0.05)$ during storage. The loss of vitamin $E$ during storage may possibly be due to the formation of peroxides during lipid oxidation. This may have occurred during processing, in the presence of oxygen during mixing and chopping of meat batters. Peroxides were degradable at higher temperatures but were stable at temperatures below $0 \mathrm{C}$; as a consequence, they can react with the vitamin E (IFST 1989).

Vitamin $\mathrm{E}$ was found to be more stable in retorted than oven-cooked beef frankfurters. This observation suggests that vitamin $E$ is highly stable to sterilization (high temperature and short time) compared with oven cooking (low temperature and long time cooking). Another reason may possibly be due to the storage conditions, where the retorted beef frankfurters were stored at room temperature while the oven-cooked beef 
Table II. Percentage reduction of vitamin E homologues for retorted beef frankfurter formulated with palmbased oils during storage for 6 months.

\begin{tabular}{|c|c|c|c|c|c|c|}
\hline \multirow{2}{*}{$\begin{array}{l}\text { Vitamin E } \\
\text { homologue }\end{array}$} & \multicolumn{6}{|c|}{ Percentage reduction $(\%)^{a}$} \\
\hline & Cooking method & Storage time & Beef fat (control) & Palm oil & RPO35 & RPO48 \\
\hline \multirow[t]{4}{*}{ a-Tocopherol } & \multirow[t]{2}{*}{ Retort } & 0 months & 100 & 36.53 & 11.45 & 38.98 \\
\hline & & 6 months & 100 & 46.86 & 43.17 & 46.19 \\
\hline & \multirow[t]{2}{*}{ Oven-cooked } & 0 months & 100 & 29.86 & 27.31 & 31.36 \\
\hline & & 6 months & 100 & 46.49 & 46.26 & 53.81 \\
\hline \multirow[t]{4}{*}{ a-Tocotrienol } & \multirow[t]{2}{*}{ Retort } & 0 months & n.c. & 33.98 & 6.59 & 35.89 \\
\hline & & 6 months & n.c. & 45.95 & 34.11 & 46.37 \\
\hline & \multirow[t]{2}{*}{ Oven-cooked } & 0 months & n.c. & 28.19 & 23.64 & 32.66 \\
\hline & & 6 months & n.c. & 47.10 & 53.10 & 57.26 \\
\hline \multirow[t]{4}{*}{ g-Tocotrienol } & \multirow[t]{2}{*}{ Retort } & 0 months & n.c. & 20.10 & 7.04 & 17.44 \\
\hline & & 6 months & n.c. & 38.17 & 29.21 & 36.67 \\
\hline & \multirow[t]{2}{*}{ Oven-cooked } & 0 months & n.c. & 29.01 & 24.31 & 32.82 \\
\hline & & 6 months & n.c. & 40.71 & 44.56 & 37.95 \\
\hline \multirow[t]{4}{*}{ d-Tocotrienol } & \multirow[t]{2}{*}{ Retort } & 0 months & n.c. & 7.06 & 1.63 & 2.2 \\
\hline & & 6 months & n.c. & 34.12 & 22.76 & 25.27 \\
\hline & \multirow[t]{2}{*}{ Oven-cooked } & 0 months & n.c. & 18.82 & 21.95 & 20.88 \\
\hline & & 6 months & n.c. & 35.29 & 41.46 & 28.57 \\
\hline \multirow[t]{4}{*}{ Total vitamin $\mathrm{E}$} & \multirow[t]{2}{*}{ Retort } & 0 months & n.c. & 25.95 & 7.24 & 26.01 \\
\hline & & 6 months & n.c. & 41.82 & 32.59 & 41.55 \\
\hline & \multirow[t]{2}{*}{ Oven-cooked } & 0 months & n.c. & 27.74 & 24.51 & 31.30 \\
\hline & & 6 months & n.c. & 43.11 & 46.61 & 45.91 \\
\hline
\end{tabular}

${ }^{a}$ Calculations are based on the values of extracted fats from sausages at 0 or 6 months, subtracted from values for initial fat raw materials, divided by the initial values of fats detected from fat raw materials. n.c., percentage reduction of vitamin $E$ in beef fat frankfurter was not calculated since all vitamin $E$ homologues except tocopherol are absent in beef fat material.

frankfurters were stored at $-18 \mathrm{C}$. According to Ottaway (1993), vitamin E is unusual in that it exhibits reduced stability at temperatures below freezing.

At high temperatures, oxygen has lower solubility in fats/oils so that autoxidative peroxide formation proceeds at lower rates and becomes gradually substituted by polymerization reactions (Marinova and Yanishlieva 1992). Another reason why vitamin $E$ is stable in retorted beef fankfurters may be due to the higher hydroperoxide (pro-oxidant) decomposition at higher temperature (Kamal-Eldin and Appelqvist 1996).

This study also showed that both a-tocopherol and a-tocotrienol decreased faster than the other two vitamin $E$ homologue in beef frankfurters. The fast reduction of atocopherol and a-tocotrienol in this study is possibly due to better antioxidant activity than the other two homologues. This also could be due to degradation of the chromanol ring of a-tocopherol and a-tocotrienol during heating due to the donation of the phenolic hydrogen to a lipid peroxyl radical (Burton et al. 1985). The presence of more methyl substituents in the phenolic ring of the a-tocopherol and a-tocotrienol does not only enhance their antioxidant activity, but also increases their lipophilic properties, making the a-homologues the most soluble vitamin E in lipid substrates (Van Acker et al. 1993). Earlier study shows that precooked patties of turkey fed with a-tocopherol supplemented diet had significantly reduced TBARS numbers in both raw and cooked burgers (by 35-50\%) during frozen storage at $-20 \mathrm{C}$ after 5 months (Wen et al. 1996). 


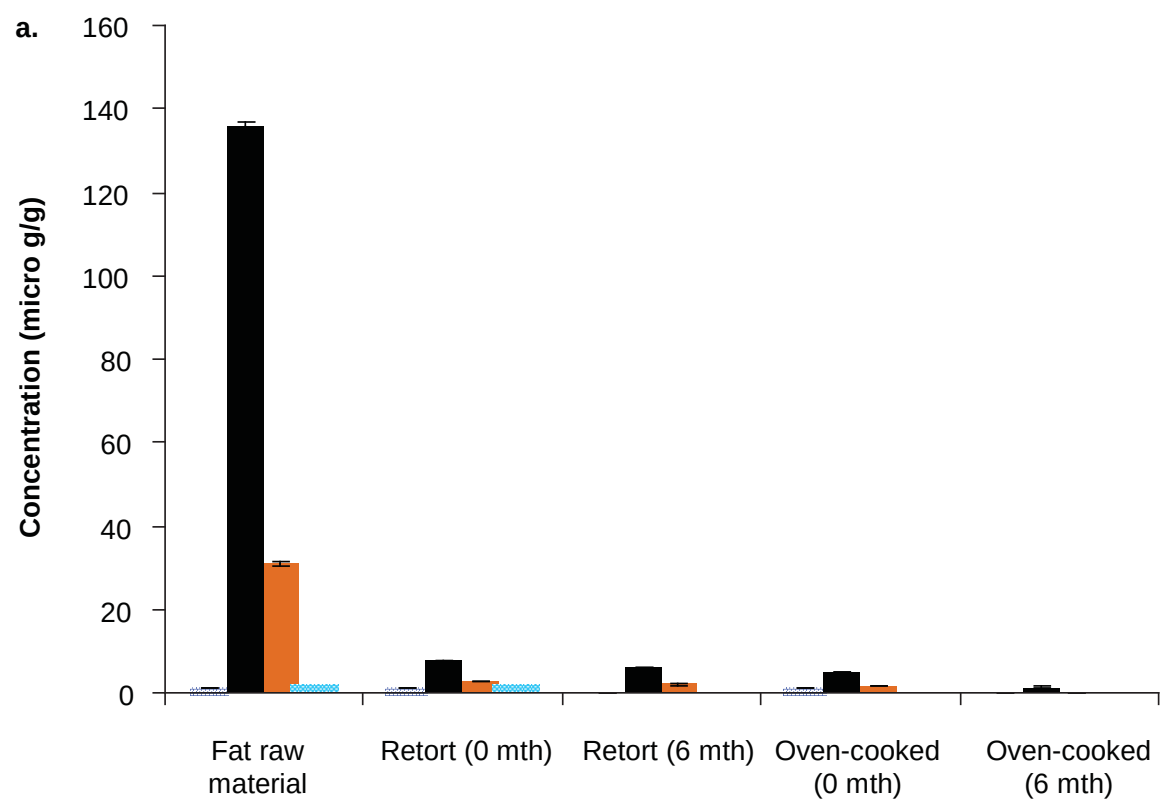

Cooking method

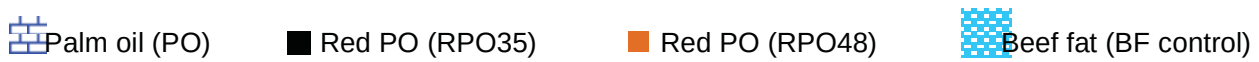

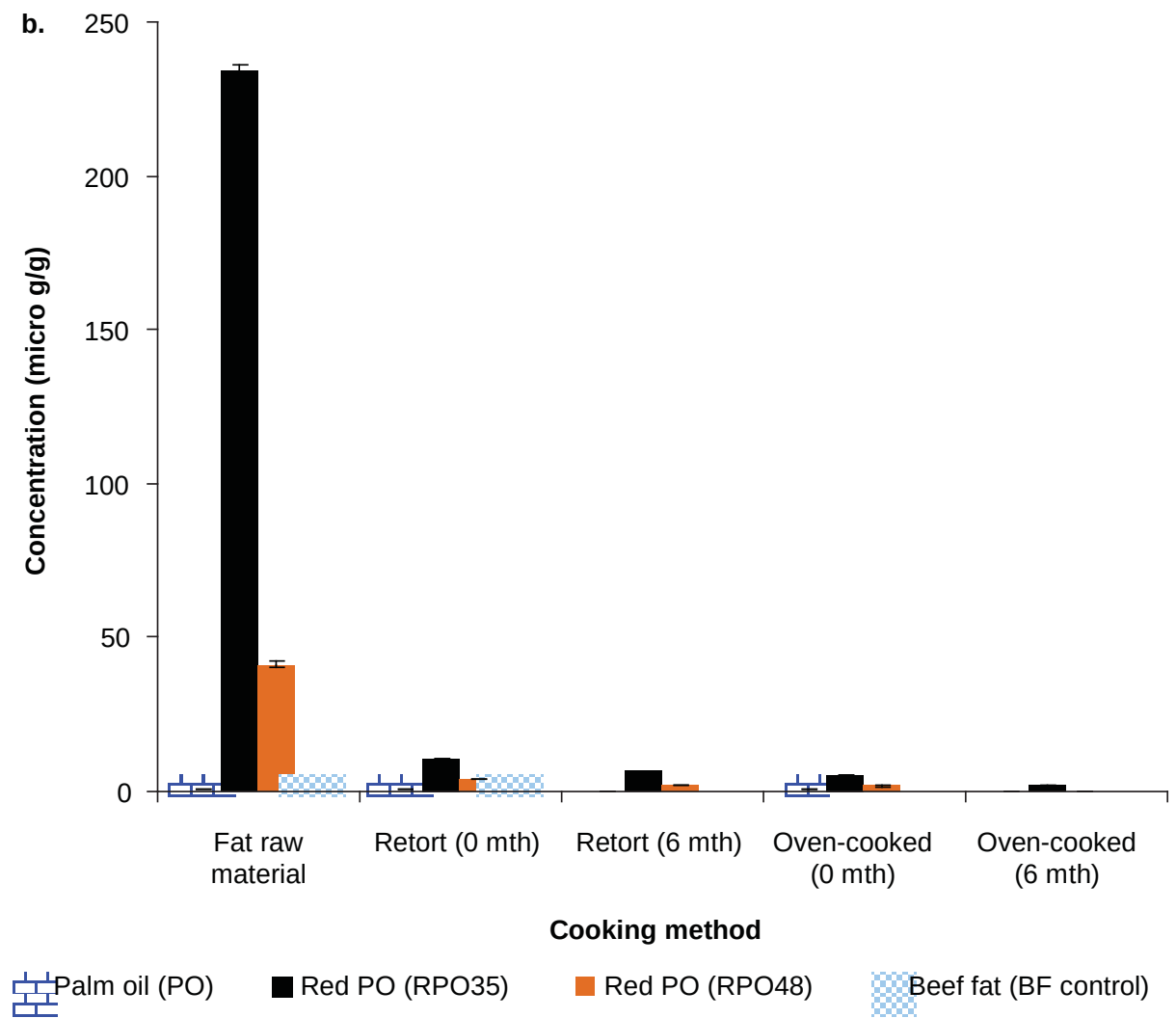

Figure 2. (Continued). 


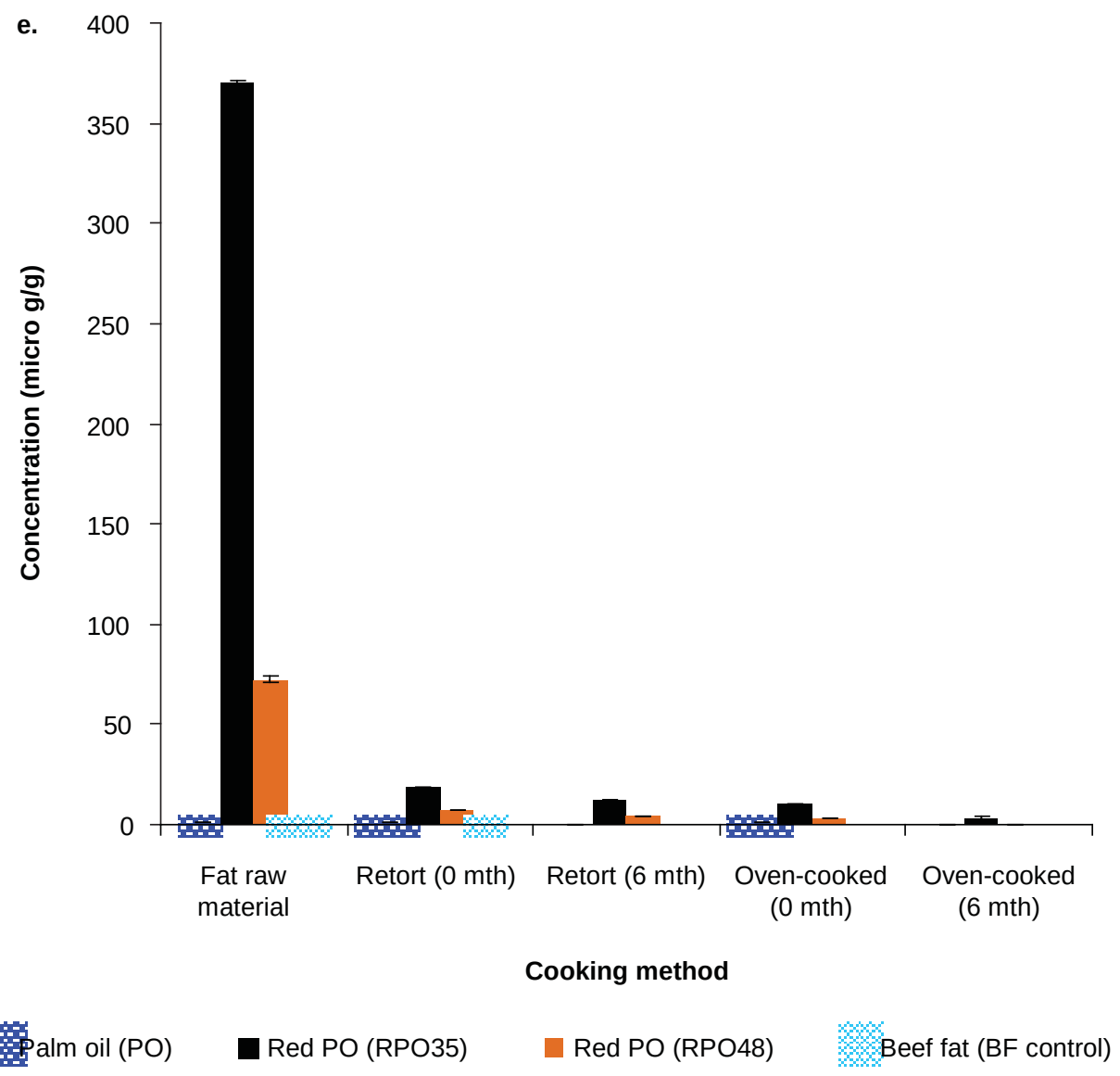

Figure 2. (a) a-Carotene content, (b) b-carotene content and (c) total carotene content of retorted and ovencooked beef frankfurters containing palm oil and RPO during storage for 6 months $\left(\begin{array}{ll}-18 & C\end{array}\right)$.

\section{Carotene content in beffankfurter}

The a-carotene content in RPO35 and RPO48 before adding into frankfurter formulation accounted for 135.6 and $31.0 \mathrm{mg} / \mathrm{g}$, respectively (Figure 2a and Table III). Meanwhile, palm oil and beef fat accounted less than $1 \mathrm{mg} / \mathrm{g}$, respectively. Generally, the percentage loss of a-carotene in all beef retorted and oven-cooked beef frankfurter blended with RPO were more than $90 \%$. However, the percentage loss of a-carotene in both RPO48 and RPO35 retorted beef frankfurters were lower than in both ovencooked beef frankfurters substituted with RPO48 and RPO35 after cooking (0 month). a-Carotene in retorted beef frankfurter blended with RPO35 lost 96\% (from 135.6 to $6.1 \mathrm{mg} / \mathrm{g}$ ), while oven-cooked beef frankfurter containing RPO35 lost 99\% (from 135.6 to $1.3 \mathrm{mg} / \mathrm{g}$ ) after 6 months of storage. A similar trend of a-carotene reduction was also detected in RPO48 retorted beef frankfurters, which lost $94 \%$ or from 31.0 to $2.0 \mathrm{mg} / \mathrm{g}$, lower than in oven-cooked frankfurters, which lost $100 \%$ (from 31.0 to $0.0 \mathrm{mg} / \mathrm{g}$ ).

b-Carotene was present in the highest amount in both raw RPO35 and RPO48 raw fat. They accounted for 234.3 and $41.3 \mathrm{mg} / \mathrm{g}$, respectively (Figure $2 \mathrm{~b}$ and Table III). The rate loss in b-carotene concentrations was similar to a-carotene. b-Carotene 
Table III. Percentage reduction of the carotene content of retorted and oven-cooked beef frankfurters containing palm oil and RPO during storage for 6 months $\left(\begin{array}{ll}-18 & \mathrm{C}\end{array}\right)$.

\begin{tabular}{|c|c|c|c|c|c|c|}
\hline \multirow[b]{2}{*}{ Carotene } & \multicolumn{6}{|c|}{ Percentage reduction $(\%)^{a}$} \\
\hline & Cooking method & Storage time & Beef fat (control) & Palm oil & RPO35 & RPO48 \\
\hline \multirow[t]{4}{*}{ a-Carotene } & \multirow[t]{2}{*}{ Retort } & 0 months & n.c. & n.c. & 94.47 & 90.65 \\
\hline & & 6 months & n.c. & n.c. & 95.50 & 93.55 \\
\hline & \multirow[t]{2}{*}{ Oven-cooked } & 0 months & n.c. & n.c. & 96.31 & 94.52 \\
\hline & & 6 months & n.c. & n.c. & 99.04 & 100 \\
\hline \multirow[t]{4}{*}{ b-Carotene } & \multirow[t]{2}{*}{ Retort } & 0 months & n.c. & n.c. & 95.39 & 90.31 \\
\hline & & 6 months & n.c. & n.c. & 97.31 & 96.16 \\
\hline & \multirow[t]{2}{*}{ Oven-cooked } & 0 months & n.c. & n.c. & 97.87 & 95.88 \\
\hline & & 6 months & n.c. & n.c. & 99.23 & 100 \\
\hline \multirow[t]{4}{*}{ Total Carotene } & \multirow[t]{2}{*}{ Retort } & 0 months & n.c. & n.c. & 95.03 & 90.32 \\
\hline & & 6 months & n.c. & n.c. & 96.68 & 94.47 \\
\hline & \multirow[t]{2}{*}{ Oven-cooked } & 0 months & n.c. & n.c. & 97.30 & 95.44 \\
\hline & & 6 months & n.c. & n.c. & 99.16 & 100 \\
\hline
\end{tabular}

${ }^{a}$ Calculations are based on the values of extracted fats from sausages at 0 or 6 months, subtracted from values for initial fat raw materials, divided by the initial values of fats detected from fat raw materials. n.c., percentage reduction not calculated since the original carotenes in fat raw material is very low.

decreased significantly $(P<0.05)$ to 10.8 and $4.0 \mathrm{mg} / \mathrm{g}(95 \%$ and $90 \%)$, respectively, in retorted beef frankfurters containing RPO35 and RPO48 after cooking (0 months). They decreased further to 6.3 and $2.0 \mathrm{mg} / \mathrm{g}$ (97\% and 95\% loss) after 6 months of storage. However, the percentage loss of b-carotene in retorted beef frankfurter was slightly lower than oven-cooked beef frankfurter substituted with palm-based oil. Cooking in the oven destroyed $98 \%$ and $96 \%$ or retained 5.0 and $1.7 \mathrm{mg} / \mathrm{g} \mathrm{b}$-carotene in beef frankfurters containing RPO35 and RFO48 at 0 months. They significantly decreased $(P<0.05)$ to 1.8 and $0.0 \mathrm{mg} / \mathrm{g}(99 \%$ and $100 \%)$, respectively, after 6 months of storage.

Total carotene concentrations in retorted beef frankfurter decreased in the range of 7.0-18.4 mg/g (90-95\% loss). However, total carotene concentrations in oven-cooked beef frankfurters substituted with RPO35 and RPO48 were significantly reduced $(\mathrm{P}<0.05)$ by $97 \%$ and $95 \%$ or dropped to 10.0 and $3.3 \mathrm{mg} / \mathrm{g}$, respectively, after 0 months of storage, and by $99 \%$ and $100 \%$ or dropped to 3.1 and $0.0 \mathrm{mg} / \mathrm{g}$, respectively, after 6 months of storage (Figure 2c and Table III). Total carotene concentrations in retorted beef frankfurters formulated with RPO35 and RPO48 decreased from 370.0 to $12.3 \mathrm{mg} / \mathrm{g}$ (97\% loss) and from 72.0 to $4.0 \mathrm{mg} / \mathrm{g}$ (95\% loss), respectively, after 6 months of storage.

The overall trend for a-carotene, b-carotene and total carotene, at 0 months, indicated lower values in oven-cooked RPO treatments, compared with retorted RPO. This could possibly be due to the longer cooking time in the oven-cooked treatments, over retorted treatments. The same trend (Table II) was also observed in all vitamin $\mathrm{E}$ values, with lower values at 0 months displayed by oven-cooked treatments, compared with retorted palm oil (exceptions were a-tocopherol and a-tocotrienol of palm oil and RPO48 at 0 months).

a-Carotene, b-carotene and total carotene degraded faster in oven-cooked beef frankfurter than in retorted beef frankfurter substituted with palm-based oil. The result also shows that a-carotene and b-carotene in beef frankfurter formulated with RPO was 
Table IV. Cholesterol content of retorted and oven-cooked beef frankfurters containing palm oil and RPO during storage for 6 months $\left(\begin{array}{ll}-18 & \mathrm{C}\end{array}\right)$.

\begin{tabular}{|c|c|c|c|c|c|}
\hline \multirow[b]{2}{*}{$\begin{array}{l}\text { Cooking } \\
\text { method }\end{array}$} & \multirow[b]{2}{*}{$\begin{array}{l}\text { Storage } \\
\text { time }\end{array}$} & \multicolumn{4}{|c|}{ Cholesterol content (mg/100 g) (percentage of reduction, \%) } \\
\hline & & $\begin{array}{l}\text { Beef fat } \\
\text { (control) }\end{array}$ & Palm oil & RPO35 & RPO48 \\
\hline & 0 months & 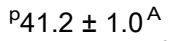 & $p_{32.2 \pm 1.3^{B}(22 \%)}$ & $p_{32.0 \pm 0.9^{B}}(22 \%)$ & $\mathrm{p}_{32.2 \pm 1.0^{\mathrm{B}}(22 \%)}$ \\
\hline \multirow[t]{2}{*}{ Retort } & 6 months & $\mathrm{pq}_{39.5} \pm 1.0^{\mathrm{A}}$ & $\mathrm{pq}_{30.2} \pm 1.7^{\mathrm{B}}(24 \%)$ & $\mathrm{pq}_{31.0} \pm 0.7^{\mathrm{B}}(22 \%)$ & $\mathrm{pq}_{30.2} \pm 1.0^{\mathrm{B}}(24 \%)$ \\
\hline & 0 months & $\mathrm{pq}_{39.5} \pm 0.7^{\mathrm{A}}$ & ${ }^{\mathrm{q}} 29.3 \pm 0.2^{\mathrm{B}}(26 \%)$ & ${ }^{\mathrm{qr}} 30.1 \pm 0.7^{\mathrm{B}}(24 \%)$ & $\mathrm{pq}_{30.3 \pm 2.7^{\mathrm{B}}(23 \%)}$ \\
\hline \multicolumn{2}{|c|}{ Oven-cooked 6 months } & ${ }^{\mathrm{q}} 38.6 \pm 0.0^{\mathrm{A}}$ & ${ }^{\mathrm{q}} 29.0 \pm 0.2^{\mathrm{B}}(25 \%)$ & ${ }^{\mathrm{r}} 29.1 \pm 0.6^{\mathrm{B}}(25 \%)$ & $\mathrm{q}_{29.1 \pm 0.5^{\mathrm{B}}(25 \%)}$ \\
\hline
\end{tabular}

Mean values within the same row bearing different uppercase superscript letters differ significantly $(P<0.05)$. Mean values within the same column bearing different lowercase superscript letters differ significantly $(P<0.05)$.

Percentage of reduction (\%) calculated based on the values of cholesterol detected in control sausages subtracted from values of cholesterol detected in palm-based fat sausages divided by the values of cholesterol detected in control sausage and multiplied by 100 .

gradually degraded upon cooking and storage. Frying of fats and oils could also lead to considerable losses of b-carotene, other carotenoids and vitamin A (Onyewu et al. 1996). The losses of carotenoid could be due to the heat during cooking; disintegrated tissue, if coupled with exposure to oxygen, light and acid, can result in the destruction of the provitamin A carotenoid (Gayatahri et al. 2004). However, b-carotene degraded with a lower rate than lycopene but faster than a-carotene (Anguelova and Warthesen 2000).

\section{Cholesterotontent}

All palm oil treatments, for retorted and oven-cooked frankfurters, at 0 and 6 months storage, were significantly lower in cholesterol values, when compared with beef fat retorted and beef fat oven-cooked frankfurters. Replacing beef fat with palm oil decreased the cholesterol level by $29.0-32.2 \mathrm{mg} / 100 \mathrm{~g} \mathrm{(22-26 \% )}$ in retorted and oven-cooked beef frankfurters (Table IV). There was no difference $(P>0.05)$ in cholesterol concentration between all frankfurters blended with palm-based oils. Other researchers reported that substituting animal fat with palm fat reduced cholesterol by $35-45 \%$ in chicken nuggets (Alina et al. 2000), 40\% in chicken burgers (Wan Sulaiman et al. 2000), 21-31\% in beef burgers (Wan Rosli et al. 2004) and 28-33\% in duck burgers (Lee et al. 2001). Replacing chicken fat in nuggets with palm fat and red palm fat also decreased the cholesterol content to 29 and $40 \mathrm{mg} / 100 \mathrm{~g}$, respectively (Nurhidayah 2001). The present study showed that there was no significant difference $(P>0.05)$ in cholesterol content within treatments, for all retorted and oven-cooked beef frankfurters during storage at 0 and 6 months. This finding was supported by Kowale et al. (1996), who reported that the initial cholesterol contents of raw, broiled and pressure-cooked mutton samples remained unchanged during refrigerated and frozen storage.

Values in the literature for the cholesterol concentrations of meats vary widely. Cholesterol values for uncooked beef longissimus steaks were in the range of 52-66 mg/ $100 \mathrm{~g}$ (Rhee et al. 1982), while cholesterol contents of raw ground beef patties were in the range of $77-92 \mathrm{mg} / 100 \mathrm{~g}$ (Hoelscher et al. 1987). This present study showed that substitution of animal fats with palm-based oils decreased the content of cholesterol in 
beef frankfurters because vegetable oils contain no cholesterol. Substituting $60 \%$ of the beef fat with peanut oil in beef frankfurters resulted in lower cholesterol content $(52-56 \mathrm{mg} / 100 \mathrm{~g})$ compared with beef frankfurters containing all beef fat, which contained $62-87 \mathrm{mg} / 100 \mathrm{~g}$ cholesterol (Marquez et al. 1989).

\section{Conclusions}

The total vitamin $\mathrm{E}$ concentration in beef frankfurters stored at $-18 \mathrm{C}$ decreased with frozen storage. Vitamin $E$ was more stable in retorted beef frankfurters than in ovencooked beef frankfurters. g-Tocotrienol and d-tocotrienol decreased faster than either g-Tocotrienol or d-tocotrienol. g-Tocotrienols and d-tocotrienols were quite stable in beef frankfurters, with the latter being a more stable homologue. Retorting and oven cooking destroy more than $90 \%$ of a-carotene and b-carotene in all beef frankfurters. However, a-carotene, b-carotene and total carotene degraded faster in oven-cooked beef frankfurter than in retorted beef frankfurter substituted with palm-based oil. In retorted and oven-cooked beef frankfurters, we successfully reduced $22-29 \%$ of cholesterol, compared with beef fat treatments. Differences of heat treatments, through oven cooking and retorting, did not significantly $(P>0.05)$ increase or decrease the cholesterol content, within treatments, at 0 and 6 months of shelf studies. In summary, the effect of cooking, frozen storage and the type of fats used could influence vitamin $E$ and carotene stability and content in beef frankfurters. This study showed the potential of utilizing RPO as animal fat analogues in improving vitamin E, reducing cholesterol but not carotenes in beef frankfurters.

Declaration of interest: The authors appreciate the funding from Universiti Sains Malaysia (304/PPSK/ 6131549), the Malaysian Palm Oil Board, the IRPA grant from MOSTE, Universiti Kebangsaan Malaysia, Carotino Sdn. Bhd. and Malaysian Agricultural Research and Development Institute (MARDI) towards the research and findings of this paper. The authors report no conflicts of interest. The authors alone are responsible for the content and writing of the paper.

\section{References}

Alina AR, Babji AS, Yusoff MSA. 2000. Some physico-chemical properties of palm fats and its effects on the quality and sensory attributes of chicken nuggets. Presented at Oils and Fats International Congress, Putra World Trade Centre, Kuala Lumpur, Malaysia, 4-8 September.

Anguelova T, Warthesen J. 2000. Degradation of lycopene, alpha-carotene and beta-carotene during lipid peroxidation. J Food Sci 65:71-75.

AOCS. 1992. Official methods and recommended practices of the American Oil Chemists' Society. 4th ed. Champaign, IL: American Oil Chemists' Society.

Babji AS, Chin SY, Seri Chempaka MY, Alina AR. 1998. Quality of mechanically deboned chicken meat frankfurter incorporated with chicken skin. Int J Food Sci Technol 49:319-326.

Babji AS, Alina AR, Mohd Suria Affandi Y, Wan Sulaiman WI. 2001. Palm oil: A healthy fat substitute? Meat Int 11:26-27.

Baydara NG, Özkan G, Yas,ar S.2007. Evaluation of the antiradical and antioxidant potential of grape extracts. Food Control 18:1131-1136.

Bohac CE, Rhee KS, Cros HR, Ono R. 1988. Assessment of methodologies for colorimetric assay of meat. J Food Sci 53:1642-1644.

Bozkurt H. 2006. Utilization of natural antioxidants: Green tea extract and Thymbra spicata oil in Turkish dry-fermented sausage. Meat Sci 73:442-450.

Burton GW, Ingold KU. 1989. Vitamin E as in vitro and in vivo antioxidant. Annual N Y Acad Sci 570:7-22. 
Burton GW, Webb A, Ingold KU. 1985. A mild, rapid, and efficient method of lipid extraction for use in determining vitamin E/lipid rations. Lipids 20:29-39.

Chiu MC, Coutinho CDM, Goncalves LAG. 2009. Carotenoids concentration of palm oil using membrane technology. Desalination 245:783-786.

Chizzolini R, Zanardi E, Dorigoni V, Ghidini S. 1999. Calorific value and cholesterol content of normal and low-fat meat and meat products. Trends Food Sci Technol 10:119-128.

Choo YM, Ma AN, Ooi CK, Yap SC, Yusuf B. 1993. Red palm oil-A carotene-rich, nutritious oil. PORIM Info Series 11:1-4.

Colmenero FJ. 1996. Technologies for developing low-fat meat products. Trends Food Sci Technol 7:41-48.

Gayatahri GN, Kalpana P, Jamuna P, Srinivasan K. 2004. Influence of antioxidant spices on the retention of beta-carotene in vegetables during domestic cooking processes. Food Chem 84:35-43.

Hart DJ, Scott KJ. 1995. Development and evaluation of an HPLC method for the analysis of carotenoids in foods, and the measurement of the carotenoid content of vegetables and fruits commonly consumed in the UK. Food Chem 54:101-111.

Hashimoto T, Kato A, Tanabe K, Namuro H, Yamoaka M, Berger KG, Ab Gapor MT. 1980. Studies on tocopherols and tocotrienols in Malaysian palm oil (I). In: Proceedings of International Symposium of the Advanced Industrial Utilization of the Tropical plants, Tsubuka, Japan, 1-4 September. Tokyo: International Research and Development Cooperation Division, Ministry of International Trade and Industry.

Hess JL. 1993. Vitamin E: Alpha-tocopherol. In Alscher RG, Hess JL, editors. Antioxidants in higher plants. Boca Raton, FL: CRC Press. pp 111-134.

Higdon JV, Frei B. 2003. Tea catechins and polyphenols: health effects, metabolism, and antioxidant functions Crit Rev Food Sci Nutr 43:89-143.

Hoelscher LM, Savell JW, Harris JM, Cross HR, Rhee KS. 1987. Effect of initial fat level and cooking method on cholesterol content and caloric value of ground beef patties. Journal of Food Science 52: 883-885.

Institute of Food Science and Technology (IFST). 1989. Nutritional Enhancement of Food-Technical Monograph No. 5. IFST, London, UK.

Jayaprakasha GK,Rao LJ. 2000. Phenolic constituents from lichen Parmotrema stuppeum (Nyl.) Hale and their antioxidant activity. Zeitschr Naturforsch 56:1018-1022.

Kamal-Eldin A, Appelqvist L. 1996. The chemistry and antioxidant properties of tocopherols and tocotrienols. Lipids 31:671-701.

Kinsella JE, Shimp JL, Mai J, Weihrauch J. 1977. Fatty acid content and composition of freshwater finfish. J Am Oil Chem Soc 54:424-429.

Kowale BN, Rao VK, Babu NP, Sharma N, Bisht GS. 1996. Lipid oxidation and cholesterol oxidation in mutton during cooking and storage. Meat Science 43:195-202.

Lee TK, Chia KL, Alina AR, Babji AS. 2001. Physico-chemical properties of duck burger blended with palm fat. Presented at 23rd Annual Conference of MSAP: Globalisation and Livestock Production in Developing Nations, The City Bayview Hotel, Langkawi, Malaysia, 27-29 May.

Lietz G, Henry CJK. 1997. A modified method to minimise losses of carotenoids and tocopherols during HPLC analysis of red palm oil. Food Chem 60:109-117.

Marcela C, De SA, Delia B, Rodriguez A. 2004. Carotenoid composition of cooked green vegetables from restaurants. Food Chem 83:595-600.

Marinova EM, Yanishlieva NV. 1992. Effect of temperature on the antioxidative action of inhibitors in lipid autoxidation. J Sci Food Agric 60:313-318.

Marquez EJ, Ahmed EM, West RL, Johnson DD. 1989. Emulsion stability and sensory quality of beef frankfurters produced at different fat or peanut oil levels. J Food Sci 54:867-870.

McCune LM, Johns T. 2002. Antioxidant activity in medicinal plants associated with the symptoms of diabetes mellitus used by the Indigenous Peoples of the North American boreal forest. J Ethnopharmacol 82:197-205.

MPOB. 1981. Malaysian Palm Oil Refining Industry, Palm Oil Refiners Association of Malaysian PORAM Technical Brochure. Kuala Lumpur: MPOB. pp 36-37.

Nurhidayah A. 2001. Production and evaluation of the quality of chicken nugget substituted with palm fat. BSc thesis, Universiti Kebangsaan Malaysia, Bangi, Malaysia.

Ollberding NJ. 2008. Changes in food sources of fat, cholesterol, and protein in the diets of adolescents with hypertension in response to a dietary intervention focusing on fruits, vegetables, and low-fat dairy foods. MSc Thesis, Universiti of Cincinnati, USA. 
Onyewu PN, Ho C, Daun H. 1996. Characterization of beta-carotene thermal degradation products in a model food system. J Am Oil Chem Soc 63:1437-1441.

Ooi CK, Choo YM, Yap SC, Ma AN. 1996. Refining of red palm oil. Elaeis 8:20-28.

Ottaway PB. 1993. Stability of vitamins in food. In: Ottaway PB, editor. The technology of vitamins in food. Cornwall: Chapman \& Hall, London, UK. pp 90-113.

Padmavathi K, Udipi SA, Rao M. 1992. Effect of different cooking methods on beat-carotene content of vegetables. J Food SciTechnol 29:137-140.

Rhee KS, Dutson TR, Smith GC, Hostetler RL, Reiser R. 1982. Cholesterol content of raw and cooked beef longissimus muscles with different degrees of marbling. Journal of Food Science 47:716-719.

Resurreccion AVA. 2004. Sensory aspects of consumer choices for meat and meat products. Meat Sci 66:11-20.

SAS. 1989. SAS user's guide: Statistics. Version 6.12. Cary, NC: SAS Institute Inc.

Sasse A, Colindres P, Brewer MS. 2009. Effect of natural and synthetic antioxidants on the oxidative stability of cooked, frozen pork patties. J Food Sci 74:S30-S35.

Tan SS, Aminah A, Zhang G. 2004. Optimizing palm oil and palm stearin utilization for sensory and textural properties of chicken frankfurters. Meat Sci 72:387-397.

Tang S, Kerry JP, Sheehan D, Buckley DJ, Morrissey PA. 2001. Antioxidative effect of added tea catechins on susceptibility of cooked red meat, poultry and fish patties to lipid oxidation. Food Res Int 34:651-657.

Van Acker SAB, Koymans LMH, Bast A. 1993. Molecular pharmacology of vitamin E: Structural aspects of antioxidant activity. Free Radic Biol Med 15:311-328.

Wan Rosli WI, Babji AS, Aminah A, Foo SP, Abd Malik O. 2004. Effects of processing on nutritional and sensory qualities of beef burgers with added palm fats. ASEAN Food J 13:83-91.

Wan Rosli WI, Babji AS, Aminah A, Foo SP, Abd Malik O. 2006. Vitamin E contents of processed meats blended with palm oils. J Food Lipids 13:186-198.

Wan Sulaiman WI, Alina AR, Babji AS, Nulkirah M, Foo SP. 2000. Effects of substituting chicken fat with palm and Carotino fats on the quality of frankfurter. Presented at 7th ASEAN Food Conference, Manila, Philippines, 19-22 November.

Wan Sulaiman WI, Alina AR, Babji AS, Nulkirah M, Foo SP. 2001. Substituting chicken fat with palm and Carotino fats in frankfurters. Meat Int 11:27-28.

Wanasundara UN, Shahidi F. 1998. Antioxidant and pro-oxidant activity of green tea extracts in marine oils. Food Chem 63:335-342.

Wen J, Morrissey PA, Buckley DJ, Sheehy PJA. 1996. Oxidative stability and alpha-tocopherol retention in turkey burgers during refrigerated and frozen storage as influenced by dietary alpha-tocopheryl acetate. Br Poultry Sci 37:787-795. 